\title{
Use and Perception of Podium Gardens in Residential Neighborhoods in Hong Kong
}

\author{
Lai Man Lui ${ }^{1}$ and Youngchul Kim ${ }^{2, *}$ \\ AGC Design Limited, Hong Kong, China; Imlui7-c@my.cityu.edu.hk \\ 2 Korea Advanced Institute of Science and Technology, Daejeon 34141, Korea \\ * Correspondence: youngchulkim@kaist.ac.kr; Tel.: +82-42-350-3636 \\ Academic Editor: Hua Qin \\ Received: 16 November 2016; Accepted: 29 December 2016; Published: 1 January 2017
}

\begin{abstract}
This paper examines how a residential podium garden design can enhance the use of a garden and the satisfaction of its users. Two public and private housing estates are selected to analyze and compare spatial use and the perception of space in podium gardens for public use. First, this paper explores the relationship between residential satisfaction and the physical conditions of podium gardens in public and private housing estates in Hong Kong. A total of 135 questionnaires are collected from two cohorts for each of these groups. People's perceptions are compared with the physical conditions of the podium gardens. Second, this paper investigates how visibility and accessibility influence the quality and usability of podium gardens. The sense of community, safety and hygiene, and accessibility are examined and compared between public and private housing estate cohorts. In conclusion, opening a podium garden to public use can promote the degree of tolerance and enhance community cohesion. Regardless of whether a podium garden is open to the public or not, according to the responses, more people using the podium garden can increase its usability. Since public monitoring can enhance safety and hygiene, podium gardens should be highly visible from the surrounding buildings. A well-planned podium design thus can improve the social and physical qualities of living environments.
\end{abstract}

Keywords: sense of community; community cohesion; satisfaction; comparison; public housing; private housing; Hong Kong

\section{Introduction}

In Hong Kong, real estate developers have recently been urged to provide more open space and communal facilities in private residential neighborhoods for public use in order to improve the social and physical quality of their living environments. Opening a residential podium garden to the public is sometimes adopted as a solution. A podium garden is an open space located at the intermediate floor of a building and generally $2-5$ stories above the ground level, forming the base of high-rise buildings. The podium and tower design emerged in Hong Kong from the UK in the 1960s. According to Shelton et al. [1], the podium tower design was once popular in Western cities, spread as far as Los Angeles, Sydney, and London, but was soon after abandoned. However, this form is still popular in Hong Kong. This building form has succeeded in fulfilling the needs of different parties. For example, as millions of migrants came to Hong Kong in the 1950s, the government settled them in high-density buildings. The podium and tower design met the demand for this. Nowadays, this design still dominates the built-up cityscape in Hong Kong. On the ground level, a commercial space was put along the streets to increase the economic efficiency of the limited land. It is easy to see shopping centers or car parks with residential tower(s) on top of them. Podium gardens have become a common separation and gate between non-domestic and domestic areas in building complexes, 
as illustrated in Figure 1. The podium space is an important urban element and has become dominant in the urban fabric of Hong Kong.

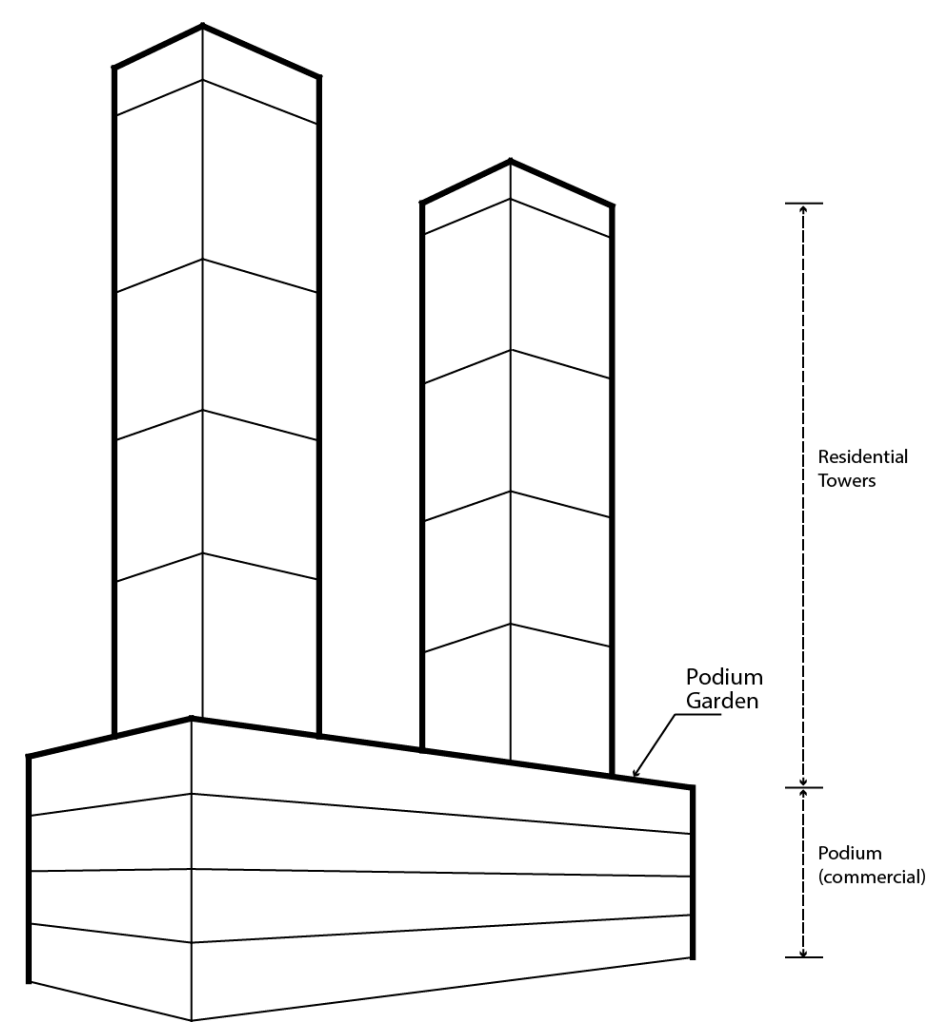

Figure 1. Podium, podium garden, and residential towers.

However, many podium gardens in Hong Kong's residential buildings are not well utilized by the communities' residents despite the fact that the podium and tower design dominates the cityscape. Shelton et al. [1] write that podium gardens can be considered a raised secondary ground space. As such, podium gardens are expected to be places for the public without potential threats. In this sense, the podium garden can encourage social interactions among citizens, increase the sense of community, and thus increase the social sustainability of the living environment. Xue et al. [2] argue that large podiums affect the urban fabric in Hong Kong and that residents' lives become detached from urban environments. Additionally, Leung et al. [3] find that podium space attracts more people than ground-street space and has become a commercial area apart from the residents' daily life in Hong Kong. The roof area of the podium space is another level between commercial and residential space, which occupies a large urban space in Hong Kong. While the aforementioned studies generally focus on podium space and the urban fabric, few studies have investigated the roof and garden space of the podium garden that is located between commercial and residential spaces. Because the podium garden is another part of the urban fabric in Hong Kong, identifying user satisfaction and uses of podium gardens would be useful to identify the urban characteristics of Hong Kong. In particular, podium gardens are located in both public and private housing estates. Accordingly, two research questions are established: how satisfied residents of public and private housing estates are with the physical conditions of their podium gardens and how visibility and accessibility influence the quality and usability of those podium gardens. Therefore, this paper aims to examine the use and perception of podium gardens to identify the podium garden's significance in the public spaces of Hong Kong. This investigation can help develop design guidelines for enhancing the use of podium gardens. 


\section{Desirable Aspects for Public Space}

This section summarizes a literature review of investigations of relevant issues to develop and manage desirable aspects for public space, including the sense of community, safety and security, and accessibility in the built environment.

\subsection{Sense of Community}

Creating a sense of community is a significant element in enhancing the social quality of living environments. McMillan \& Chavis [4] defined a sense of community as the emotional perception and belief of belonging, attachment, and commitment to a group. A sense of community promotes the exchange of information and ideas in a community, and increases accessibility to resources and opportunities, which enhances community cohesion [5]. Indicators of community cohesion are the extent to which residents recognize their neighbors, the degree to which they care about their community, and the level at which they participate in community activities [6,7]. Thus, an attractive podium garden can promote a sense of community. Many group activities take place in podium gardens, such as tai-chi practice, dancing practice, flea markets, and chess games. These activities can facilitate social interactions between people who already know each other and between people meeting for the first time. Since podium gardens provide a safe and comfortable environment for people to meet their neighbors, they can help build positive relationships between users. For example, residents in old housing estates gather and interact frequently in large podium gardens because it is part of where people pass by every day, where people chat with their neighbors and where community events are held. These podium gardens help bond the community in old housing estates in Hong Kong.

\subsection{Safety and Secutiry}

Safety and security are important factors influencing usability of a podium garden and the satisfaction of its users. According to Miethe [8], a major factor that causes people to withdraw from open space is the fear of crime. In Western cities, podium and tower designs failed because of the socioeconomic conditions and environmental conditions: thieves, drug users, and hooligans hid in podium gardens and they became unsafe living environments. However, Lucy and Philips [9] stated that increasing community cohesion could lower crime by providing support and public monitoring, and in turn increase the property values of the place. Greene and Greene's survey also showed that belonging to a neighborhood was important for providing a sense of security [10]. Creating a neighborhood can act as a public monitoring on people and their activities in public space. In addition, increasing the visibility of a podium garden can promote a sense of openness and safety. With high visibility, a podium garden's users feel secure and safe under public monitoring. According to Greene and Greene [10], six variables are involved in the feeling of security in a public open space: straight or curved roads, the presence of crossroads, the presence of trees, the transparency of fences, lighting, and the presence of other people. These variables are all related to visibility in a space. Thus, spatial visibility is an important element in determining safety and security in a space.

\subsection{Accessibility}

Accessibility is a spatial measure to demonstrate how conveniently a space can be reached or passed through. If openness and visibility of a space increase, its accessibility will be higher [11]. The Hong Kong Public Space Initiative [12] illustrates that public space is to comprise a pyramid from a foundation of accessibility to the environment and facility, to public utilization, and to sociability. To achieve sociability in a public space, accessibility, environment and facilities, and public utilization should be achieved in order. In particular, accessibility is a foundation to achieve sociability in a public space. Accordingly, a convenient location to use, a connection to public transport, a highly visible condition to the public, a clear entrance, and a barrier-free approach are desirable conditions of an appropriately accessible podium garden. If a podium garden is developed with easily accessible 
conditions, users can enhance their social activities to meet and interact with neighbors. This spatial condition can improve the use of the space and likely improve social cohesion. In particular, providing various approaches to a podium space can attract more users. The various facilitates to connect to a podium garden include a walking path, a public transit system, a parking area, and so on.

\section{Methods}

This paper examines how a residential podium garden design can increase the use of a garden and the satisfaction of its users. A combined method that consists of qualitative and correlational strategies is adopted. Data collection tactics include a questionnaire, on-site observation, and syntactical analysis. Two housing estates were selected to analyze and compare spatial uses and perceptions of podium gardens for public use: Kwai Shing East Estate and Kwai Chung Plaza Blocks, located in the same district, the Kwai Chung district in Hong Kong. Since the two housing estates are located in the same district, the surrounding contexts have a similar urban fabric.

First, this paper explores the relationship between user satisfaction and the physical conditions of podium gardens in public and private housing estates in Hong Kong. A total of 135 questionnaires were collected for the two cases: 88 for the public podium garden at Kwai Shing East Estate and 47 for the private podium garden at Kwai Chung Plaza Blocks. A random sampling was applied. Respondents were randomly chosen in person at sites including podium gardens, shopping malls under the podium garden, and residential block lobbies and entrances. After a short explanation, respondents completed the questionnaire at the sites without any intervention. The questionnaire consisted of three parts: general information, the sense of community, and the perception of podium garden. The general information comprised gender, age, the number of years living in their housing estate, and the number of families the respondent knows in the same community. A 5-point Likert-type scale was used to analyze the sense of community and the perception of the podium garden. People's behaviors and perceptions of both the public and the private housing estates were each compared with the physical conditions of the podium gardens.

Second, this paper investigates how visibility and accessibility influence the quality and usability of podium gardens. An integrated approach is adopted to evaluate both social and physical qualities. The sense of community, safety, and accessibility are examined and compared among public and private housing estates. In particular, the space syntax theory is adopted, which is a set of theories and methods for analyzing spatial configurations. Hillier and Hanson [13] state that the spatial configurations are correlated with the social-cultural meaning of space and human movements in space. In this paper, a visibility graph and axial-line map analyses are adopted, which are popular and effectively illustrate spatial configurations in highly dense environments (e.g., Parvin et al. [14]; Ueno et al. [15]).

The visibility graph is a method to illustrate visual areas and visual relationships between vantage points. Visibility is important in designing a podium garden for controlling security and hygiene conditions. Generally, the visibility inside the podium garden is low due to blockage by vegetation, fences, and curvy paths. Thus, visibility from a higher level is found to be another significant element in controlling the environment. Distances and angles between the podium and residential blocks are significant for increasing visibility from a higher level. The visibility graph effectively illustrates a heat map of visibility in the area and shows the amount of area seen from a certain vantage point.

The axial-line map is a method for identifying topological connections and relationships between spaces. Axial lines effectively illustrate links between spaces and formulate a network between spaces in the area. Given the network, spatial accessibility is calculated and examined in terms of the extent to which people can easily access each space. By representing the values in the network, the axial-line maps effectively visualize links and weights as a network. 


\section{Analyzing the Public and the Private Housing Estates}

\subsection{Responses between the Public versus Private Housing Estates}

\subsubsection{The Sense of Community}

Table 1 compares the means of users' responses between the public and the private podium spaces. First, the mean number of families that respondents in the public estate knew is 20.03, which is substantially higher than that in the private estate-11.83 $(p<0.05)$. The mean number of families that public podium users always contact with, 5.86, is slightly higher than that in the private estate, $4.13(p<0.1)$. Second, both sets of respondents generally regard their community as those who live in the same estate and within a five-minute walk distance. Those who live in the public housing estate support this meaning of community more than those in the private housing estate $(p<0.05)$. Third, responses regarding community activities are not statistically different. Although both sets of respondents generally like their communities, their degrees of participation are neutral. In the public and the private housing estates, community participation, regarding respondent participation, is around 2.85 and 2.94, respectively, and, regarding neighbor participation in their community, 3.23 and 3.00 , respectively, both of which are not statistically different $(p>0.1)$. While both sets of residents like their communities, at 3.75 and 3.68 for public and private housing estates, respectively, their willingness to be involved in, and their perception of, community participation are not strongly supportive.

Table 1. Comparison of responses between the public and the private estates.

\begin{tabular}{|c|c|c|c|c|}
\hline & Public $\left(n_{1}=88\right)$ & Private $\left(n_{2}=47\right)$ & $t$-Value & Sig. (2-Tailed) \\
\hline \multicolumn{5}{|l|}{ Part A. Sense of Community } \\
\hline Q1 Number of years living in the housing estate & 14.70 & 17.57 & -1.301 & 0.196 \\
\hline Q2 Number of families you know & 20.03 & 11.83 & 3.089 & $0.002 * *$ \\
\hline \multicolumn{5}{|l|}{ 1. Meanings of community } \\
\hline (1) live in the same building & 3.66 & 3.89 & -1.435 & 0.154 \\
\hline (2) live in the same estate & 4.30 & 4.00 & 2.282 & $0.024 * *$ \\
\hline \multicolumn{5}{|l|}{ 2. Community participation } \\
\hline (1) You actively participate in community activities & 2.85 & 2.94 & -0.466 & 0.642 \\
\hline (2) People in the same community actively participate in community activities & 3.23 & 3.00 & 1.501 & 0.136 \\
\hline (3) You like your community & 3.75 & 3.68 & 0.548 & 0.585 \\
\hline \multicolumn{5}{|l|}{ Part B. Perception of Podium Garden } \\
\hline \multicolumn{5}{|l|}{ 2. Meanings of podium garden } \\
\hline (1) You enjoy social activities in the podium garden & 3.53 & 2.74 & 4.569 & 0.000 ** \\
\hline (2) The podium garden helps bond the community & 3.88 & 3.06 & 5.774 & $0.000^{* *}$ \\
\hline (3) The openness of podium garden to the public & 4.09 & 2.21 & 11.921 & $0.000 * *$ \\
\hline (4) You wish more people would use this podium garden & 3.57 & 3.49 & 0.412 & 0.681 \\
\hline \multicolumn{5}{|l|}{ 3. Security and hygiene concerns } \\
\hline (1) You can clearly see the podium garden from your home & 2.77 & 3.43 & -2.927 & $0.004^{* *}$ \\
\hline (2) You are concerned about security problems in the podium garden & 2.55 & 2.89 & -1.755 & $0.081 *$ \\
\hline (3) You are concerned about hygiene problems in the podium garden & 3.09 & 2.87 & 1.044 & 0.298 \\
\hline (4) There will be less crime if the podium garden has high visibility & 3.82 & 3.66 & 1.180 & 0.240 \\
\hline (5) Hygiene will be better if the podium garden has high visibility & 3.56 & 3.60 & -0.226 & 0.822 \\
\hline (6) A podium garden should be easily accessible to the public & 4.33 & 3.43 & 6.262 & $0.000^{* *}$ \\
\hline
\end{tabular}

\subsubsection{Perception of Podium Garden}

Regarding activities in the podium space, the public podium users more frequently visit the podium garden than do private users. The means of the public case are statistically higher than those of the private case with a confidence level of 0.95 . In addition, public podium users more positively perceive the podium garden than do private users, although they similarly agree that they want to 
have more people in the podium garden. Regarding responses as to whether they wish more people would use the podium garden, more than half of the respondents in both the public and the private housing estates wish more people would use the podium garden, while a quarter of them do not.

However, private podium users consider the podium garden to belong to the residents and their estates. The mean of openness to the public is 4.09 for public podium users and 2.21 for private podium users and those means are statistically different with a confidence level of 0.95 . Furthermore, the respondents in the private housing estate were asked whether they are willing to open (part of) their podium garden to the public for a limited time if security and hygiene would not deteriorate. Forty-two percent of respondents were not willing to open their podium to the public, while $35 \%$ of them are. The mean is 2.81 , and the standard deviation is 1.19 . The private podium users were not willing to open the podium garden to the public. Private podium users are concerned about the problems of safety and hygiene that may arise if their podium is opened to the public.

Regardless of whether a podium garden is open to the public or not, attracting more people to a podium garden can increase its use and the satisfaction of the community. First, according to the responses in Part B, the perception of the podium garden in Table 1, public podium users more actively use the podium garden than do private podium users. More respondents from the public estate enjoy the social aspects of the podium garden, at 3.53, than those from the private estate, $2.74(p<0.05)$. Second, both sets of respondents wish more people would use the podium garden, at 3.57 and 3.49 for the public and private estates, respectively. Although private podium users are concerned about the safety and hygiene conditions, they also support more people using the podium. Additionally, private podium users were asked to answer the additional question of whether they would be willing to open (part of) their podium garden to the public for a limited time if security and hygiene did not deteriorate. According to Table 2, more than half of the private podium users do not oppose opening their podium garden to the public for a limited time if the security and hygiene did not deteriorate. That means they are tolerant to strangers if the security and hygiene of the podium are under control. In order to increase the usability of the private podium garden, which are low according to the activities on the podium garden, as seen in Table 1, opening it to the public is one solution. This might increase the number of users, make the podium garden public and more social, and hence increase the sense of community in the podium garden.

Table 2. Responses of the private garden users on opening the podium garden to the public.

\begin{tabular}{cccccc}
\hline & Strongly Disagree & Disagree & Neutral & Agree & Strongly Agree \\
\hline Counts & 8 & 12 & 10 & 15 & 2 \\
$\%$ & 17.0 & 25.5 & 21.3 & 31.9 & 4.3 \\
\hline
\end{tabular}

\subsection{Spatial Configurations between the Public and the Private Housing Estates}

\subsubsection{Visibility}

Kwai Shing East Estate, the public case in Figure 2, has wider and higher visibility than does Kwai Chung Plaza Blocks, the private case in Figure 3. In Kwai Shing East Estate, highly connected and integrated areas are widely distributed around the podium space. However, in Kwai Chung Plaza Blocks, a long narrow space is highly connected and integrated while other areas are segregated. To analyze visibility, the space syntax method was used. At the podium level, visibility measures in the space syntax method illustrate the spatial relationship of people's visual perception in the podium garden. According to Table 3, the results of the visibility analysis demonstrate that the mean values of visual connectivity and integration of Kwai Shing East Estate, the public housing estate, are higher than those of Kwai Chung Plaza Blocks, the private housing estate, as presented in Table 3. The mean values of visual connectivity and integration of Kwai Shing East Estate are 1271.63 and 8.8205 and those of Kwai Chung Plaza Blocks are 1149.26 and 7.3742. These results show that the public housing 
estate offers better visual connective and integration, which demonstrates that people can more easily use the podium space in this estate.

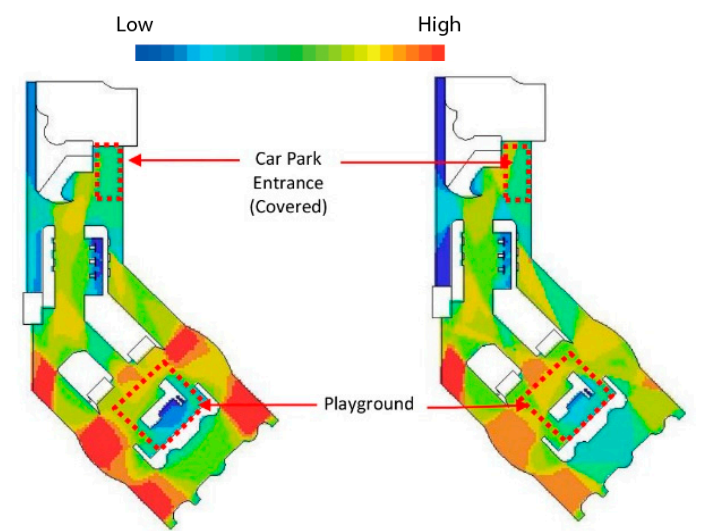

(a)

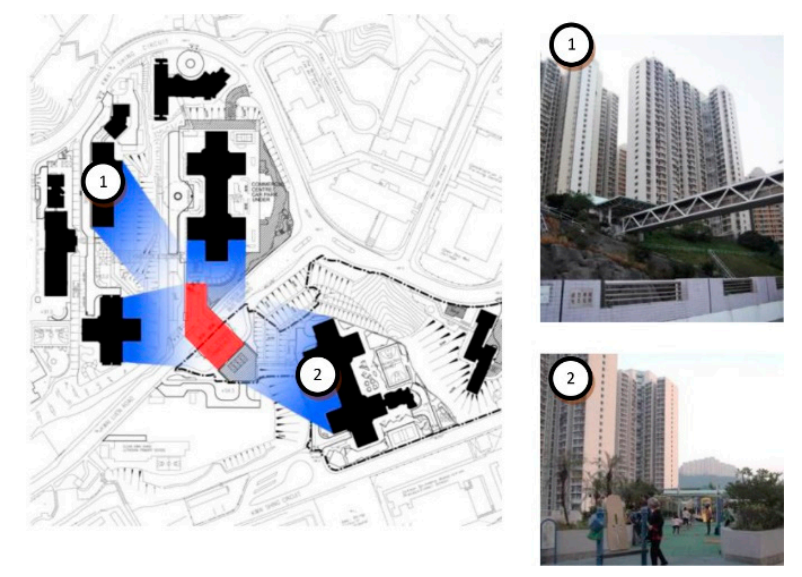

(b)

Figure 2. Visibility of Kwai Shing East Estate. (a) Visual connectivity and visual integration; (b) Visibility from a high level.

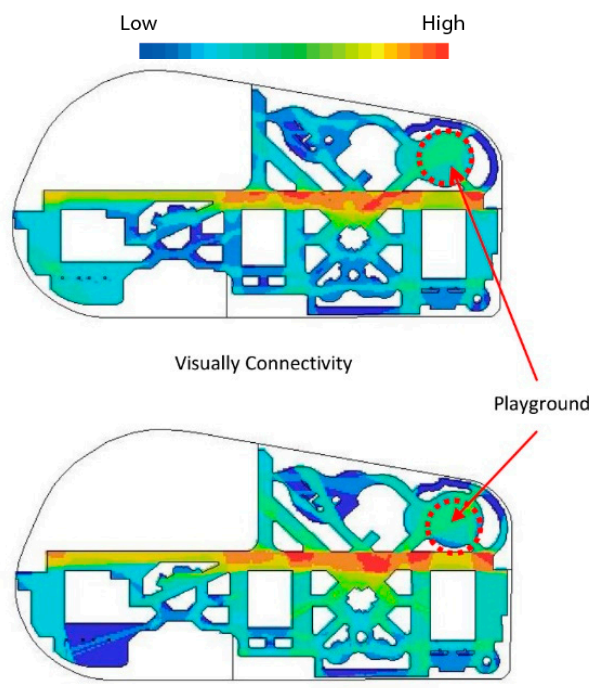

Visually Integration

(a)

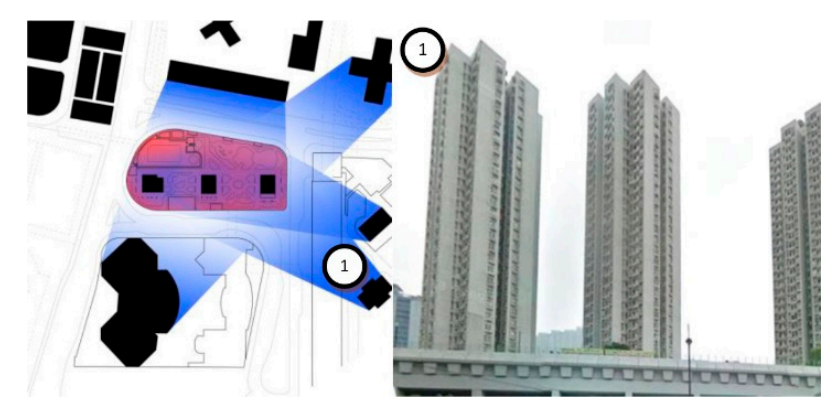

Figure 3. Visibility of Kwai Chung Plaza Blocks. (a) Visual connectivity and visual integration; (b) Visibility from a high level.

Table 3. Comparison of visual connectivity, and visual integration.

\begin{tabular}{cccc}
\hline & & Kwai Shing East Estate (Public) & Kwai Chung Plaza Blocks (Private) \\
\hline \multirow{3}{*}{ Visual connectivity } & Min. & 9.00 & 44.00 \\
& Mean & 1271.63 & 1149.26 \\
& Max. & 2066.00 & 3392.00 \\
\hline \multirow{3}{*}{ Visual integration } & Min. & 4.0039 & 4.1574 \\
& Mean & 8.8205 & 7.3742 \\
& Max. & 12.5717 & 12.6410 \\
\hline
\end{tabular}

In addition, safety and hygiene problems, such as piles of trash, are found where areas have low visibility or covered areas in the podium garden. However, although they are more visually separated, 
the playgrounds are still clean and safe. While children's playgrounds in both the public and the private housing estates have relatively low values of visual connectivity and visual integration at the podium level in Figure 3, the children's playgrounds are easily observed from the surrounding housing flats at a higher level. The tall residential buildings are stood around the children's playgrounds, which are easily noticeable from higher levels.

\subsubsection{Accessibility}

In Kwai Shing East Estate, the podium garden is connected to a bus terminal via vertical circulation. In Figure 4, the connectivity graph shows that people can easily reach the podium garden from the bus terminal. It takes three steps to move from the bus terminal to the podium garden, while it takes more steps from the bus terminal to the residential blocks. Additionally, residents can choose various routes to go home through the podium, the shopping mall, or the streets.

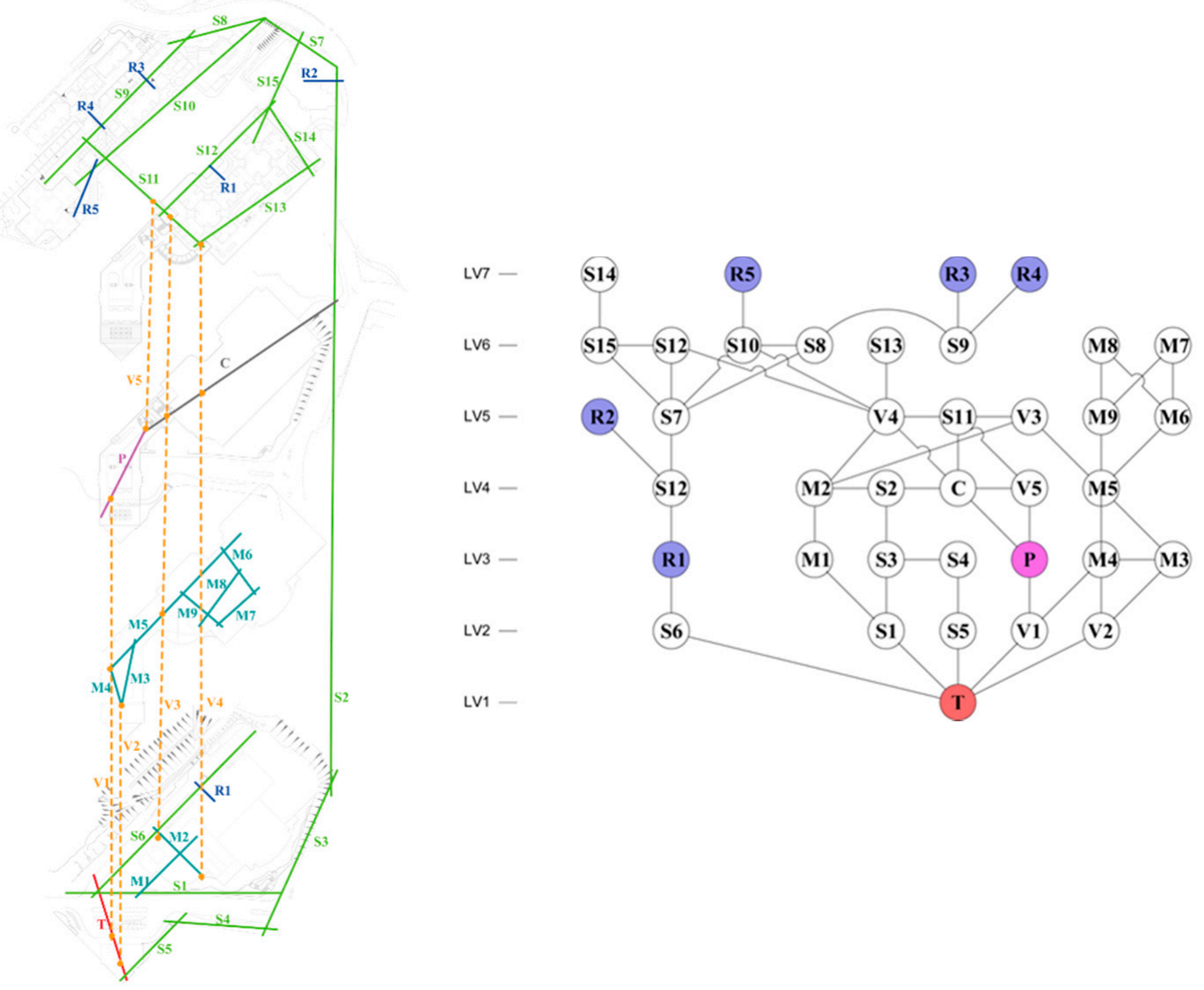

Figure 4. Connectivity of Kwai Shing East Estate ( $\mathrm{C}=$ Car park; $\mathrm{M}=$ Shopping mall; $\mathrm{P}=$ Podium; $\mathrm{R}=$ Residential blocks; $\mathrm{S}=$ Street; $\mathrm{T}=$ Public transport; $\mathrm{V}=$ Vertical circulation).

In Kwai Chung Plaza Blocks, Kwai Fong MTR Station and several minibus stops are located next to the housing estate in Figure 5. However, the podium garden is not directly connected to public transportation stops. The podium garden is separated from both residents and public users. The connectivity graphs illustrate that residents can go home directly without passing through the podium garden. It takes five steps to move from the MTR station to the podium garden. The position of the residential blocks is shallower than that of the podium garden. It takes fewer steps to move from the MTR station to the residential block. The accessibility to the podium garden is lower than that to the residential blocks. 

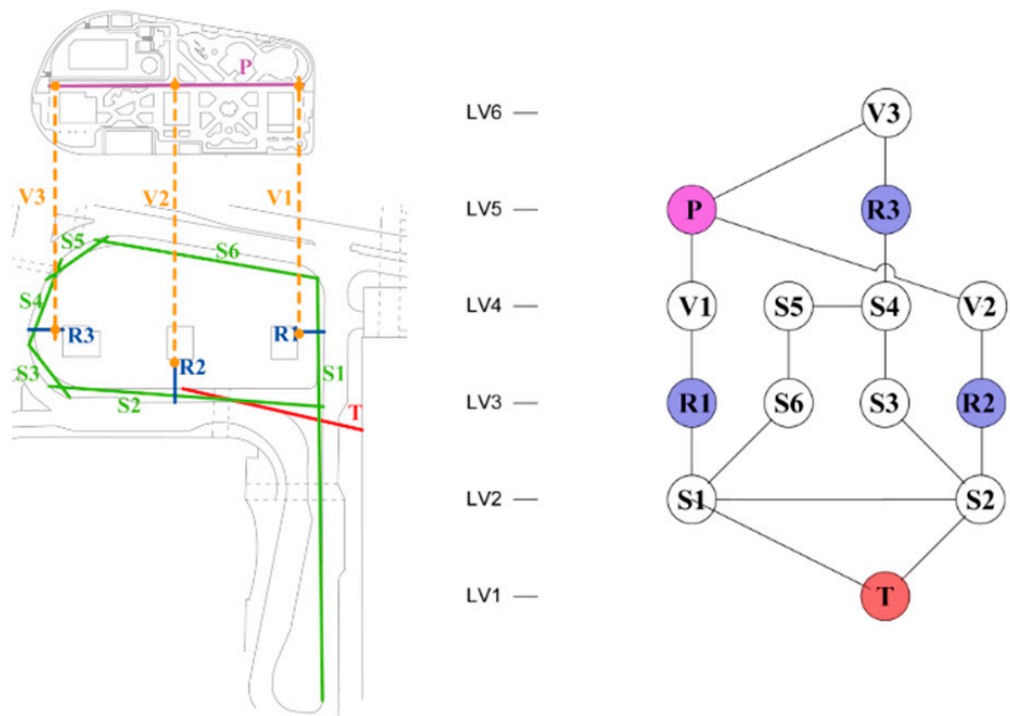

Figure 5. Connectivity of Kwai Chung Plaza Blocks ( $\mathrm{P}=$ Podium; $\mathrm{R}=$ Residential blocks; $\mathrm{S}=\mathrm{Street}$; $\mathrm{T}=$ Public transport; $\mathrm{V}=$ Vertical circulation).

\section{Discussion and Conclusions}

Table 4 summarizes the findings regarding the sense of community, visibility, and accessibility at Kwai Shing East Estate and Kwai Chung Plaza Blocks. The sense of community and the usability of the podium garden in Kwai Shing East Estate, a public housing estate, are relatively higher than those in Kwai Chung Plaza Block, a private housing estate. Visibility at both the podium and the higher levels in the public housing estate are relatively higher than that in the private housing estate. While safety concerns in the public housing estate are relatively lower than those in the private housing estate, hygiene concerns in the public housing estates are relatively higher than those in the private housing estate. While residents in the public housing estate welcome strangers in their podium garden, they are more concerned about the hygiene conditions in their garden. Residents in the private housing estates show less concern about hygiene and believe that their podium garden is well maintained. Regarding the location of a podium garden, when the podium garden is integrated with the residents' approach to their home, residents will be able to easily access the podium garden on the way to the residential block.

Table 4. Sense of community, visibility, and accessibility.

\begin{tabular}{|c|c|c|}
\hline & Kwai Shing East Estate (Public) & Kwai Chung Plaza Blocks (Private) \\
\hline Usability of podium garden & High & Low \\
\hline Sense of community & Relatively higher & Relatively lower \\
\hline Visibility (podium level) & Relatively higher & Relatively higher \\
\hline Visibility (higher level) & High & Low \\
\hline Safety concern & Relatively lower & Relatively higher \\
\hline Hygiene concern & Relatively higher & Relatively lower \\
\hline Accessibility by residents & High & Moderate \\
\hline Accessibility by the public & Moderate & Low \\
\hline \multicolumn{3}{|c|}{$\begin{array}{l}\text { (1) } \mathrm{T} \rightarrow \mathrm{R} \\
\text { (2) } \mathrm{T} \rightarrow \mathrm{P} \\
\text { (3) } \mathrm{T} \rightarrow \mathrm{P} \rightarrow \mathrm{R} \\
\text { (4) } \mathrm{T} \rightarrow \mathrm{M} \rightarrow \mathrm{R} \\
\text { (5) } \mathrm{T} \rightarrow \mathrm{M} \rightarrow \mathrm{P}\end{array}$} \\
\hline
\end{tabular}


According to the findings, opening a podium garden can enhance community cohesion. An appropriately accessible podium garden can attract more users and enhance social activities and interactions, which can increase people' sense of community. As more people become active in the podium garden, residents have greater chances of developing community interaction in the podium garden. If the podium garden is more accessible, more people will go there and more social activities will take place.

Furthermore, improving public monitoring and avoiding hidden space in podium gardens can enhance safety and security. The more visible the podium space is, the safer and cleaner it will be. The podium also should be highly visible from the surrounding environment. This relates to the visual angle and the distance from the surroundings. Using proper day-lighting and artificial-lighting is also important for keeping the podium garden visible and observable. Thus, determining an appropriate opening hour of the podium garden in private developments would be an appropriate strategy to ensure the safety of the environment. As visibility falls at night, the space will no longer be under public monitoring.

Moreover, connecting a podium garden to public transportation stops can increase accessibility to, and thus the usability of, the podium garden. By attracting more users to the podium garden, more social interactions will occur and the sense of community can be enhanced.

In Hong Kong, as podium spaces are rapidly becoming dominant, an increasing number of segregated private podium gardens are being built. Opening a residential podium garden to the public can provide a balance between public and private areas. Opening a podium garden for public use can promote a degree of tolerance and enhance community cohesion. With public monitoring for safety and hygiene, podium gardens can be highly visible from the surrounding environment. In addition, connecting a residential podium garden to public transportation systems can enhance accessibility for public use. A well-planned podium design thus is important to improve the social and physical qualities of the living environment.

Accordingly, we propose a set of design strategies to optimize the usability of residential podium gardens and the satisfaction of its users. These design strategies comprise visibility, accessibility, and management. First, visibility of the podium is important to promote a sense of safety. A podium garden should be highly visible from the surrounding environment and housing flats. The surrounding buildings and the podium garden should be in close proximity to ensure an increased degree of visibility from high levels. Unimpeded views are ideal. Second, visual connections should be considered between different functional spaces in the podium garden. The height of plantings and fences should be adjusted to avoid view obstructions. Fences with transparent materials could be used. Third, a suitable gradient can create visual connections between different levels. Inappropriate gradients might hinder continuous vision inside the podium, which might lower visibility and public monitoring. Fourth, the whole podium garden should be illuminated to ensure high visibility and public monitoring. Admitting daylight is important for a podium garden. Transparent materials can be selected for a canopy to control weather conditions. Pedestrian-scale lighting can be adopted to illuminate podium gardens at night. Fifth, a podium garden should be easily noticeable to people with clear guidance. A podium garden should be located close to residential blocks while providing residents with route choices to pass through the podium on their way home. Sixth, connecting a podium garden to public transportation systems can attract more people and enhance social interactions. Seventh, podium garden's entrances should be wide and welcoming. The entrances should be as wide as possible in order to enhance the accessibility and usability of the space.

This paper is a preliminary investigation to examine the use and perception of podium gardens in public and private housing estates. We have no claim to generalize the findings to illustrate public and private housing estates in Hong Kong. However, these initial findings and suggestions can help improve the spatial conditions of podium gardens in Hong Kong. 
Acknowledgments: This paper is supported by a grant from Korea Advanced Institute of Science and Technology (KAIST, Project No. G04150046). The opinions, findings, conclusions, and recommendations expressed in this paper are those of the authors and do not necessarily reflect the view of KAIST.

Author Contributions: All authors participated in conducting the research from establishing research topic and design, developing method and analyzing data. All authors discussed and finalized the results to prepare the manuscript according to the research progress.

Conflicts of Interest: The authors declare no conflict of interest.

\section{References}

1. Shelton, B.; Karakiewicz, J.; Kvan, T. The Making of Hong Kong: From Vertical to Volumetric; Routledge: Abingdon, UK, 2013.

2. Xue, C.Q.; Zhai, H.; Roberts, J. An urban island floating on the MTR station: A case study of the West Kowloon development in Hong Kong. Urban Des. Int. 2010, 15, 191-207. [CrossRef]

3. Leung, S.M.S.; Kim, T.W.; Kim, Y. Linked podiums affecting street life: A case of Tuen Mun in Hong Kong. Urban Des. Int. 2016. [CrossRef]

4. McMillan, D.W.; Chavis, D.M. Sense of community: A definition and theory. J. Community Psychol. 1986, 14, 6-23. [CrossRef]

5. Lund, H. Pedestrian environments and sense of community. J. Plan. Educ. Res. 2002, 21, 301-312. [CrossRef]

6. Cochrun, S. Understanding and enhancing neighbourhood sense of community. J. Plan. Lit. 1994, 9, 92-99. [CrossRef]

7. Local Government Association (LGA). Community Cohesion Action Guide; Local Government Association (LGA): London, UK, 2004.

8. Miethe, T.D. Fear and withdrawal from urban life. Ann. Am. Acad. Political Soc. Sci. 1995, 539, $14-27$. [CrossRef]

9. Lucy, W.H.; Phillips, D.L. Tomorrow's Cities, Tomorrow's Suburbs; American Planning Association Planners Press: Chicago, IL, USA, 2006.

10. Greene, M.; Greene, R. Urban safety in residential areas: Global spatial impact and local self-organising processes. In Proceedings of the 4th International Space Syntax Symposium, London, UK, 17-19 June 2003.

11. Development Bureau. Report on Consultancy Study on Public Open Space in Private Developments [POSPD]. The Government of the Hong Kong Special Administrative Region. Available online: http:/ /www.devb.gov. hk/filemanager/en/content_582/Consultant_Report_English.pdf (accessed on 30 December 2016).

12. Hong Kong Public Space Initiative. The Ideal Public Space. Available online: http://www.hkpsi.org/eng/ publicspace/ideal/ (accessed on 30 December 2016).

13. Hillier, B.; Hanson, J. The Social Logic of Space; Cambridge University Press: Cambridge, UK, 1984.

14. Parvin, A.; Ye, A.M.; Jia, B. Effect of visibility on multilevel movement: A study of the high-density compact built environment in Hong Kong. Urban Des. Int. 2008, 13, 169-181. [CrossRef]

15. Ueno, J.; Nakazawa, A.; Kishimoto, T. An analysis of pedestrian movement in multilevel complex by space syntax theory-in the case of Shibuya station. In Proceedings of the 7th International Space Syntax Symposium, Stockholm, Sweden, 8-11 June 2009.

(C) 2017 by the authors; licensee MDPI, Basel, Switzerland. This article is an open access article distributed under the terms and conditions of the Creative Commons Attribution (CC-BY) license (http://creativecommons.org/licenses/by/4.0/). 